\title{
THE INTERNATIONAL TRANSMISSION OF VOLATILITY SHOCKS: AN EMPIRICAL ANALYSIS
}

\author{
Haroon Mumtaz \\ Queen Mary College
}

\section{Konstantinos Theodoridis}

Bank of England

\begin{abstract}
This paper proposes an empirical model which can be used to estimate the international transmission of volatility shocks. Using this model we estimate that a one standard deviation increase in the volatility of the shock to US real GDP leads to a decline in UK GDP of $1 \%$ relative to trend and a $0.7 \%$ increase in UK CPI relative to trend at the two-year horizon. Using a nonlinear open-economy DSGE model, we find that these empirical estimates are consistent with the response to a perturbation to the volatility of foreign "supply" type shocks, while an increase in the volatility of demand shocks has a negligible impact. (JEL: JEL, F42, F47, C32)
\end{abstract}

\section{Introduction}

A vast body of empirical research has focused on estimating the domestic impact of structural economic shocks originating from the rest of the world. Structural vector autoregressions, (S)VARs, originally proposed by Sims (1980), have featured prominently in this literature as they offer a flexible data-driven approach to modeling the international transmission mechanism. Prominent papers that adopt this approach include VAR studies by Cushman and Zha (1997), Kim (2001), and Scholl and Uhlig (2008) amongst many others.

While the international transmission mechanism of these shocks has been studied deeply, the role played by changes in the volatility of these shocks has been ignored in this literature. Most of the adopted SVAR models in these papers assume homoskedastic

The editor in charge of this paper was Fabio Canova.

Acknowledgments: The views expressed in this paper are those of the authors, and not necessarily those of the Bank of England. We would like to thank Fabio Canova, Charlotta Groth, Tony Yates, Emilio FernandezCorugedo, Matthias Paustian, Pawel Zabczyk, Martin Andreasen, Juan Rubio-Ramirez, Richard Clarida, Andrew Blake, Richard Harrison, Paulet Sadler, Simon Price, Giancarlo Corsetti, Susanto Basu, Brent Bundick, John Williams, Bruce Preston, Pedro Gomis Porqueras, Nick Bloom, Gunes Kamber, Christoph Thoenissen, Ozer Karagedikli, John McDermott, the participants of the SIRE econometrics workshop series, and anonymous referees for their useful comments and suggestions. Charlotte Dendy provided excellent research assistance.

E-mail: h.mumtaz@qmul.ac.uk (Mumtaz); Konstantinos.Theodoridis@ bankofengland.co.uk (Theodoridis) 
shocks. Studies that do allow for time-varying shock volatility (see for example Mumtaz and Sunder-Plassmann 2010) do not incorporate a direct impact of the shock variance on the endogenous variables. Given that a growing body of theoretical work (see for example Fernandez-Villaverde et al. 2009) has identified various channels through which changes in volatility can affect the real economy, the omission of this possible source of international shock transmission is a potential problem.

This paper attempts to fill this gap in the literature by using an extended SVAR model to estimate the effect of an increase in the volatility of shocks to US real activity on the UK economy. The extensions to the SVAR model proposed in this paper include: (1) allowing for time-varying variance of structural shocks via a stochastic volatility specification and (2) by allowing a dynamic interaction between the level of the endogenous variables in the VAR and this time-varying volatility. This extended VAR model can therefore be used to not only gauge the effect of foreign shocks but also the impact of changes in the volatility of the shock in question.

We focus the paper on the potential impact of the volatility of shocks to US real activity because of the policy relevance of this question. In particular, during the recent recession and financial crisis, uncertainty about growth in the United States (and the euro area) has been a key concern for policy makers. The methodology proposed in this paper is used to quantify the potential impact of this uncertainty.

Using this extended SVAR model we find that a one standard deviation increase in the volatility of US real activity shocks has a persistent impact on the UK economy and leads to a $1 \%$ decline in UK GDP relative to trend at the two-year horizon. In contrast, UK CPI inflation increases and CPI level rises by $0.7 \%$ relative to trend at the two-year horizon.

We next use a nonlinear small open-economy New Keynesian DSGE model calibrated to the US and UK economies to investigate what kind of structural uncertainty shock could generate the dynamic behavior obtained by the empirical model. The model simulations illustrate that supply type volatility shocks in the United States can produce the negative conditional co-movement in UK inflation and output. In the model, UK inflation rises as a result of supply volatility shocks because firms and workers bid up wages and prices to hedge against unfavorable Calvo contracts. In addition, an increase in wage and price dispersion makes production less efficient and causes marginal costs to rise in the United Kingdom. Output falls because agents are risk averse and save more in the face of rising uncertainty. In contrast, we find that innovations to the volatility of US demand type shocks have a negligible impact on the UK economy.

The analysis in the paper adds to the literature on international transmission by systematically investigating the cross-country impact of uncertainty. In addition, the analysis generalizes the empirical and theoretical literature on the real effects of uncertainty shocks by considering an international channel of transmission. Finally, the empirical model proposed in the paper builds upon existing VAR models by simultaneously allowing the estimation of time-varying shock volatility and the impact of this volatility on the endogenous variables. 
Our results have important implications. Our finding that volatility shocks lead to a negative co-movement between output and inflation highlights the fact that the impact of uncertainty may not always resemble the effect of demand shocks and thus supports the conclusions reached in Fernandez-Villaverde et al. (2011b). This is important from a policy perspective because it suggests that these shocks cannot be easily mitigated by the monetary authorities due to the negative trade-off between inflation and output. Our results also offer an explanation of why: (i) inflation in the United Kingdom remained elevated (on average) during the great recession while GDP contracted significantly and (ii) recovery has been so slow.

The paper is organized as follows: Sections 2 and 3 introduce the SVAR model and discuss the estimation method. The results from the VAR model are presented in Section 4. We introduce the open-economy DSGE model in Section 5 and present the model simulation in Section 5.4.

\section{Empirical Model}

We estimate the following VAR model with stochastic volatility:

$$
Z_{t}=c+\tau_{t}+\sum_{j=1}^{P} \beta_{j} Z_{t-j}+\sum_{j=0}^{J} \gamma_{j} \tilde{h}_{t-j}+\Omega_{t}^{1 / 2} e_{t}, \quad e_{t} \sim N(0,1),
$$

where

$$
\Omega_{t}=A^{-1} H_{t} A^{-1^{\prime}}
$$

In equation (1) $c$ denotes intercepts, $\tau_{t}$ is a linear time trend, $Z_{t}$ denotes the $N$ macroeconomic variables (log US GDP growth, log US CPI, the federal funds rate, $\log$ UK GDP, $\log$ UK CPI, and Bank Rate in our benchmark application that follows), while $\tilde{h}_{t}=\left[h_{1 t}, h_{2 t}, \ldots, h_{N t}\right]$ refers to the log volatility of the structural shocks in the VAR. This latter feature can be seen more clearly by considering our application where $N=6$. The structure of $H_{t}$ in equation (2) is then given by

$$
H_{t}=\left(\begin{array}{cccccc}
\exp \left(h_{1 t}\right) & 0 & 0 & 0 & 0 & 0 \\
0 & \exp \left(h_{2 t}\right) & 0 & 0 & 0 & 0 \\
0 & 0 & \exp \left(h_{3 t}\right) & 0 & 0 & 0 \\
0 & 0 & 0 & \exp \left(h_{4 t}\right) & 0 & 0 \\
0 & 0 & 0 & 0 & \exp \left(h_{5 t}\right) & 0 \\
0 & 0 & 0 & 0 & 0 & \exp \left(h_{6 t}\right)
\end{array}\right)
$$

The structure of the $A$ matrix is chosen by the econometrician to model the contemporaneous relationship amongst the reduced-form shocks. We discuss our choice of the structure of the $A$ matrix in Section 3.2. 
The transition equation for the stochastic volatility is given by

$$
\tilde{h}_{t}=\alpha+\theta \tilde{h}_{t-1}+\eta_{t}, \quad \eta_{t} \sim N(0, Q), \quad E\left(e_{t}, \eta_{t}\right)=0
$$

where $\alpha$ is a vector of constants and $\theta$ is a diagonal matrix implying that each element of $\tilde{h}_{t}$ follows an $\mathrm{AR}(1)$ process. There are two noteworthy features about the complete system defined by equations (1), (2), and (4). First, equation (1) allows the volatility of the structural shocks $\tilde{h}_{t}$ to have an impact on the endogenous variables $Z_{t}$. In our specification the log volatility enters the VAR equations rather than its level. This is primarily because the level of the volatility is sensitive to scaling of the endogenous variables which can sometimes result in computational instability. Second, note that the structure of the matrix $A$ in equation (2) determines the interpretation of structural shocks and hence their volatility $H_{t}$. In the previous six-variable example with $Z_{t}$ containing US GDP, US CPI, the federal funds rate, UK GDP, UK CPI, and Bank Rate (in that order), a lower triangular structure for $A_{t}$ would imply that one could interpret $h_{1 t}$ as the log volatility of the shock to US real activity, where this shock is identified via the assumption that UK shocks have no contemporaneous impact on US real activity. The ability to place an economic interpretation on some or all of the shocks is important as it allows the model to tackle the analysis of the impact of volatility in a theoretically consistent manner.

Note that equation (4) makes the simplifying assumption that the shocks to the volatility equation $\eta_{t}$ and the observation equation $e_{t}$ are uncorrelated and $Q$ is a diagonal matrix. With these assumptions in place, one can interpret an innovation in $\eta_{t}$ as a shock to volatility of the structural shock of interest and then calculate the response of $h_{t}$ and $Z_{t}$. On the other hand, if these assumptions are relaxed, further identifying restrictions are required to distinguish amongst the volatility shocks and to separate the innovation to the volatility from the innovation to the level. Note that in this more general scenario (i.e., with a full covariance matrix amongst the volatility and level innovations), identification of the volatility shocks is substantially more involved. In particular, there is no simple way to assign elements of $\tilde{h}_{t}$ to a particular structural shock (as done in the previously proposed model) and the researcher has to take a stand on the restrictions to place on the contemporaneous relationships amongst the volatilities. In contrast, the assumptions in equation (4) allow the use of standard identification schemes (that apply to the contemporaneous relationships amongst the level of the reduced-form shocks rather than their volatility). To retain this ease of interpretation of $\tilde{h}_{t}$ we incorporate the assumption of a diagonal $Q$ and no correlation between $e_{t}$ and $\eta_{t}$ in the benchmark empirical model.

The time series model considered in this section may be seen as a simplification of the reduced-form version of a small open-economy DSGE model with stochastic volatility. The studies of Fernandez-Villaverde et al. (2011a,b) and FernandezVillaverde and Rubio-Ramirez (2010) argue that in order to study the effects of volatility on a DSGE economy we are required to approximate agents' decision rule at least up to the third order. This approximation of the DSGE model expresses the endogenous variables as functions of the volatility shocks. In our empirical model, this 
relationship is summarized by matrices $\gamma_{j}$. Note however, that the mapping from the theoretical to empirical model is not one to one, as there are several nonlinear terms in the third-order approximation that are not included in equation (1). However, the time series model appears rich enough to capture the macroeconomic aggregates responses to uncertainty perturbations. We show in the Online Appendix that when the VAR is estimated on data generated from a nonlinear DSGE model, the VAR estimates of the impulse response to a volatility shock match the underlying DSGE responses quite closely.

The previously proposed model is related to a number of recent contributions. For example, the structure of the stochastic volatility model used closely resembles the formulations used in time-varying VAR models (see Cogley and Sargent 2005; Primiceri 2005). Our model differs from these studies in that it allows a direct impact of the volatilities on the level of the endogenous variables. The proposed model can be thought of as a multivariate extension of the stochastic volatility in mean model proposed in Koopman and Uspensky (2000) and applied in Berument, Yalcin, and Yildirim (2009), Kwiatkowski (2010) and Lemoine and Mougin (2010). In addition, our model has similarities with the stochastic volatility models with leverage studied in Asai and McAleer (2009) and the nonlinear model proposed in Aruoba, Bocola, and Schorfheide (2011). However, unlike these contributions, the proposed model is formulated with the aim of characterizing the dynamic effects of volatility of structural shocks.

This feature also distinguishes our empirical model from those used in Bloom (2009), Leduc and Liu (2012), Colombo (2013), and Alexopoulos and Cohen (2009). These papers estimate VARs augmented with measures of economic uncertainty that are calculated independently of the empirical model. Examples of such measures include estimates of stock market volatility (Bloom 2009; Leduc and Liu 2012) and an economic uncertainty series based on textual analysis (Alexopoulos and Cohen 2009). The volatility measures used in these VARs are by construction more general than the stochastic volatility associated with an orthogonalized shock to an endogenous variable in the empirical model. In other words, the empirical model used in this paper focuses on the impact of innovations to the volatility of structural shocks of interest rather than attempting to analyze the effect of an increase in economic uncertainty.

\section{Estimation}

\subsection{The Gibbs Sampling Algorithm}

The nonlinear state-space model consisting of the observation equation (1) and transition equation (4) is estimated using a Gibbs sampling algorithm. The Online Appendix presents details of the priors and the conditional posterior distributions while a summary of the algorithm is presented in what follows.

The Gibbs sampling algorithm proceeds in the following steps: 
1. Conditional on a draw for the stochastic volatility $\tilde{h}_{t}$, and the matrix $A$, equation (1) represents a VAR model where the disturbances are heteroskedastic and correlated with the regressors $\tilde{h}_{t}$ (if the contemporaneous value of $\tilde{h}_{t}$ is included in the righthand side of equation (1)). However, conditional on $\tilde{h}_{t}$, and the matrix $A$, the form of heteroskedasticity and this correlation is known and can be removed via a simple GLS transformation of the model. Once this is done, standard results for conditional posterior distribution of the VAR coefficients apply to $\Gamma=[c, \beta, \gamma]$. Note that we use rejection sampling to impose stability on the VAR coefficients.

2. Conditional on a draw for $\tilde{h}_{t}$ and $\Gamma$, and assuming a lower triangular structure for $A$, the elements of this matrix can be drawn using methods for linear regression models that describe the relationship amongst the elements of the residual matrix $v_{i t}=\Omega_{t}^{1 / 2} e_{i t}$ as shown in Cogley and Sargent (2005). Conditional on $\tilde{h}_{t}$, the constants $\alpha_{i}$, autoregressive parameters $\theta_{i}$, and variances $Q_{i}$ can be drawn using standard results for linear regressions.

3. Conditional on $\Gamma, A, \theta_{i}$, and $Q_{i}$, the stochastic volatilities are simulated using a date by date independence Metropolis step as described in Cogley and Sargent (2005) and Jacquier, Polson, and Rossi (1994) (see also Carlin, Polson, and Stoffer 1992).

We use 100,000 replications and base our inference on the last 10,000 replications. The recursive means of the retained draws (see Online Appendix) show little fluctuation, providing support for convergence of the algorithm.

\subsection{Model Specification and the Identification of the Shock to US Real Activity}

In our application, the vector of endogenous variables $Z_{t}$ contains quarterly data on $\log$ US GDP, $\log$ US CPI, the federal funds rate, log UK GDP, log UK CPI, and the Bank Rate over the period 1975Q1 to 2011Q3. The US data are obtained from the FRED database. The FRED codes are as follows: (1) Real GDP: GDPC96, (2) CPI: CPIAUCSL, (3) Federal Funds rate: FEDFUNDS. UK real GDP is obtained from the Office for National Statistics (code ABMI). UK CPI and Bank Rate are obtained from the Bank of England database.

We employ the following benchmark VAR specification:

$$
Z_{t}=c+\tau_{t}+\sum_{j=1}^{2} \beta_{j} Z_{t-j}+\sum_{j=0}^{1} \gamma_{j} \tilde{h}_{t-j}+\Omega_{t}^{1 / 2} e_{t} .
$$

The structure of the prior on $\beta$ and the $\gamma$ matrices (described in the Online Appendix) incorporates a small open-economy assumption for the United Kingdom. In particular, we incorporate the prior belief that the lagged UK variables and (lagged and contemporaneous) stochastic volatilities have a negligible impact on the United States. 
The lag length of the endogenous variables is set at two, reflecting convention in studies employing similar VAR models to quarterly data (see for example Cogley and Sargent 2005; Primiceri 2005). In our benchmark model, the contemporaneous and the lagged value of $\tilde{h}_{i t}$ is allowed to affect $Z_{t}$. Given that we employ quarterly data, we allow the possibility of an impact of $\tilde{h}_{t}$ within a three-month period. We show in the sensitivity analysis that the benchmark results are not affected if longer lags of volatility are included in the mean equations.

In order to identify the US real activity shock we consider the following recursive structure for $\tilde{A}=A^{-1}$ :

$$
\tilde{A}=\left(\begin{array}{cccccc}
1 & 0 & 0 & 0 & 0 & 0 \\
\tilde{a}_{2,1} & 1 & 0 & 0 & 0 & 0 \\
\tilde{a}_{3,1} & \tilde{a}_{3,2} & 1 & 0 & 0 & 0 \\
\tilde{a}_{4,1} & \tilde{a}_{4,2} & \tilde{a}_{4,3} & 1 & 0 & 0 \\
\tilde{a}_{5,1} & \tilde{a}_{5,2} & \tilde{a}_{5,3} & \tilde{a}_{5,4} & 1 & 0 \\
\tilde{a}_{6,1} & \tilde{a}_{6,2} & \tilde{a}_{6,3} & \tilde{a}_{6,4} & \tilde{a}_{6,5} & 1
\end{array}\right) .
$$

Given the ordering of the endogenous variables (as US GDP, US CPI, the federal funds rate, UK GDP, UK CPI, and Bank Rate) this structure for $\tilde{A}$ implies that the first shock is identified as an exogenous innovation in US real activity. As described in the following sensitivity analysis, the results do not change substantially when US GDP growth is ordered second or third within the US block. Note that since the United Kingdom is ordered after the United States, shocks to the UK economy have no contemporaneous impact on the United States. This, together with the a priori structure of the lagged coefficient matrices, implements a small open-economy restriction for the UK.

The structure of $\tilde{A}$ identifies a shock to US real activity but does not provide information about the source of the shock. In order to infer the possible source, we use the nonlinear DSGE model in Section 5. In particular, we use simulations from the model to analyze the response to an increase in the volatility of this shock and consider alternative sources of the shock within the model. This approach is in the spirit of identification via sign restrictions in the sense that we investigate which shocks in the DSGE model match the VAR responses. However, the caveat of the approach is that this investigation is done ex post and the DSGE sign restrictions are not imposed directly on $\tilde{A} .^{1}$

1. In our setting, this agnostic approach has a distinct computational advantage. Imposing a full set of sign restrictions implies a nonrecursive structure for $\tilde{A}$ which implies that step 2 of the Gibbs sampler described in Section 3 becomes substantially more involved. Unlike a standard VAR model, $\tilde{A}$ cannot be rotated post-estimation to impose sign restrictions. This is because changes to $\tilde{A}$ have an impact on the stochastic volatility which in turn affects the VAR coefficients as it enters the VAR equations. Note that Canova and Forero (2012) present an algorithm to sample the elements of a nonrecursive $\tilde{A}$ with zero restrictions in the context of time-varying VAR model. 


\section{Results}

\subsection{The Impact of US Real Activity Volatility Shocks on the UK Economy}

We first compare the fit of the benchmark model with a standard BVAR with stochastic volatility - that is, a model where the stochastic volatility does not affect the endogenous variables. The model comparison is carried out via the Bayesian deviance information criterion (DIC). Introduced in Spiegelhalter et al. (2002), the DIC is a generalization of the Akaike information criterion-it penalizes model complexity while rewarding fit to the data. As described in the Online Appendix, the DIC can be calculated as $D I C=\bar{D}+p_{D}$ where $\bar{D}$ measures goodness of fit and $p_{D}$ approximates model complexity. A model with a lower DIC is preferred. The restricted model has an estimated model complexity $p_{D}$ equal to 104.22 and its DIC estimate is -549.92 . In contrast, the benchmark model has a higher estimated model complexity with a $p_{D}$ equal to 121.67. However, the goodness of fit of the benchmark model more than compensates for this increase in complexity and the estimated DIC equals -857.01 . This indicates strong evidence in favor of the model that allows the volatility of shocks to affect the endogenous variables.

Figure 1 presents the estimated volatility of the shock to US GDP where this shock is identified using the recursive structure in equation (6). The volatility of this shock is highest in the pre-1985 period reaching its peak during the late $1970 \mathrm{~s}$. The post-1985 period contains smaller increases at the time of the first Gulf war during the early 1990s, the recession of 2000 and then towards the end of the sample coinciding with the recent financial crisis. It is interesting to note that this shock volatility displays a reasonable correlation with the policy uncertainty index proposed in Baker, Bloom, and Davis (2012), especially over the recent financial crisis.

Figure 2 plots the impulse response (median and the $68 \%$ highest posterior density intervals, HPDI) to a one standard deviation increase in the variance of the US real activity shock. A one standard deviation shock increases the log volatility of the real activity shock by around $20 \%$. It is worth noting from Figure 1 that the increase in the $\log$ variance of this shock over the crisis period (2008Q1 to 2009Q1) was approximately $50 \%$.

The shock generates a negative co-movement between GDP and CPI in both countries. GDP declines in the United States and United Kingdom by about $1 \%$ at the two-year horizon. The magnitude of this decline is similar to that estimated by Christiano, Motto, and Rostagno (2014) after a one standard deviation increase in cross-sectional idiosyncratic uncertainty and to the fall in production due to a volatility shock reported in Bloom (2009). The level of CPI is estimated to increase by about $0.7 \%$ at the two-year horizon in both countries two years after the shock with the implied increase in inflation equaling about $0.1 \%$.

Tables 1 and 2 present the estimated contribution of the US real activity volatility shock to the forecast error variance (FEV) of the endogenous variables. At short horizons, the contribution of the volatility shock is small with the maximum share 


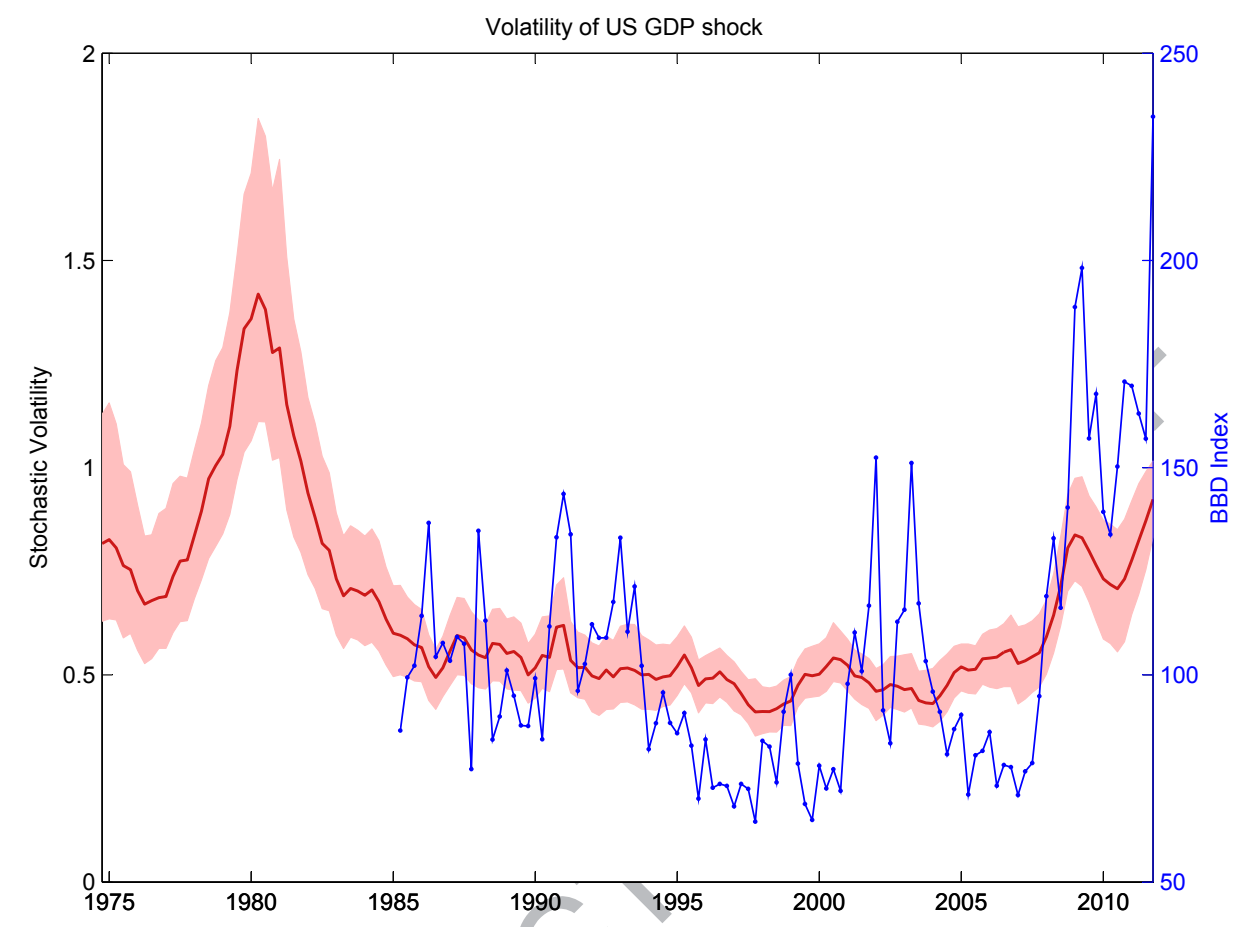

FIGURE 1. Standard deviation of shock to the US GDP VAR equation. BBD index refers to the policy uncertainty measure proposed in Baker, Bloom, and Davis (2012).

TABLE 1. Contribution of US real activity volatility shocks to the forecast error variance of US variables.

\begin{tabular}{lccc}
\hline Horizon & GDP & CPI & Federal funds rate \\
\hline $1 \mathrm{Q}$ & 0.674 & 2.316 & 0.1423 \\
& $(0.15,2.80)$ & $(0.86,4.59)$ & $(0.13,0.74)$ \\
$4 \mathrm{Q}$ & 3.901 & 8.482 & 0.6954 \\
& $(0.52,12.65)$ & $(4.42,15.16)$ & $(0.07,3.65)$ \\
$8 \mathrm{Q}$ & 8.167 & 15.530 & 1.8651 \\
& $(1.37,22.51)$ & $(7.44,27.65)$ & $(0.22,9.31)$ \\
$12 \mathrm{Q}$ & 11.819 & 21.590 & 2.9536 \\
& $(2.48,29.58)$ & $(9.82,37.04)$ & $(0.38,13.65)$ \\
\hline
\end{tabular}

around 2\%. At the two-year horizon, this shock contributes about $10 \%$ to GDP of both countries. In contrast, the contribution of this shock to the federal funds rate and the bank rate remains negligible. The volatility shock appears to be more important at longer horizons-its contribution to US GDP FEV is around $12 \%$ at the three-year horizon. Similarly, the shock contributes about $12 \%$ to the FEV of UK GDP. These estimates are similar to those found by Christiano, Motto, and Rostagno (2014) who 

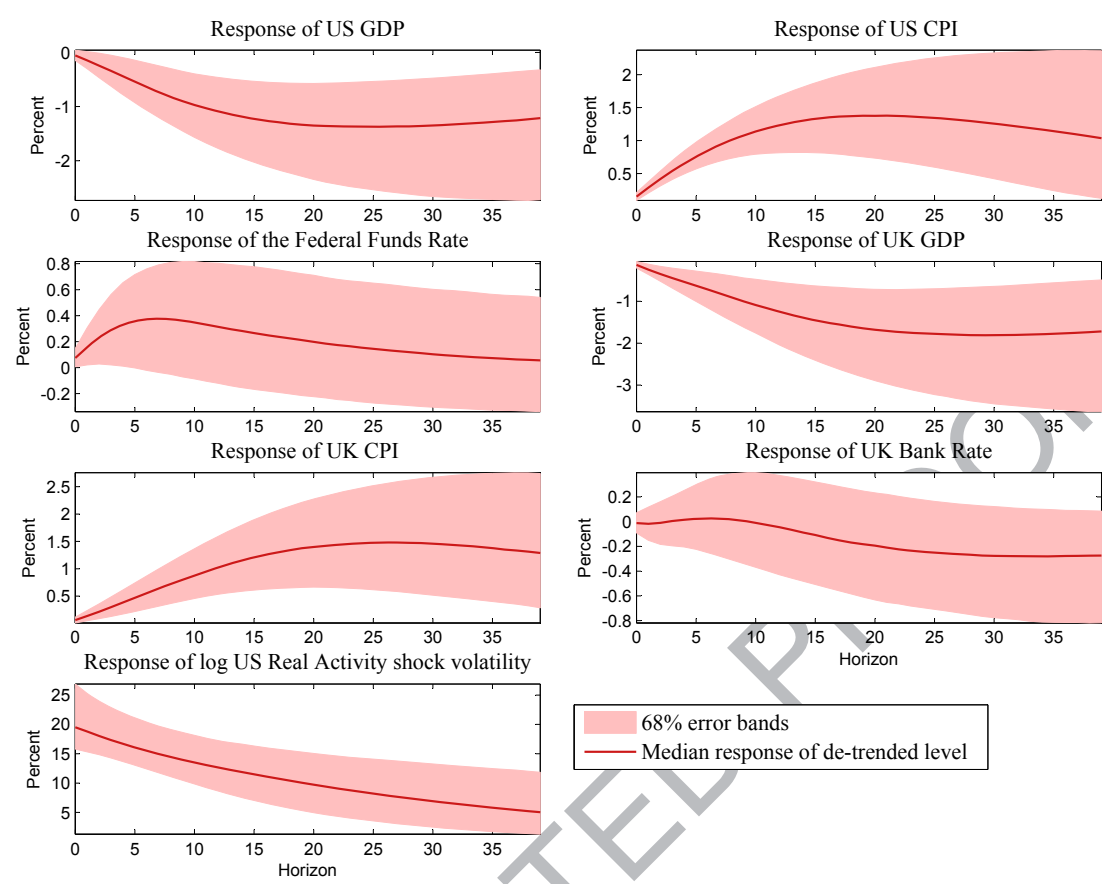

FIGURE 2. Impulse response to a shock to the volatility of US output using the benchmark VAR model. The impulse responses are expressed in percentage terms.

TABLE 2. Contribution of US real activity volatility shocks to the forecast error variance of UK variables.

\begin{tabular}{lccc}
\hline Horizon & GDP & CPI & Policy Rate \\
\hline \multirow{2}{*}{$1 \mathrm{Q}$} & 1.652 & 0.5563 & 0.0428 \\
& $(0.27,4.2)$ & $(0.06,2.15)$ & $(0.003,0.19)$ \\
$4 \mathrm{Q}$ & 6.335 & 3.217 & 0.1927 \\
& $(1.52,14.07)$ & $(0.62,8.86)$ & $(0.03,0.78)$ \\
$8 \mathrm{Q}$ & 9.950 & 6.705 & 0.5229 \\
& $(2.22,23.01)$ & $(1.61,16.15)$ & $(0.10,2.02)$ \\
$12 \mathrm{Q}$ & 11.988 & 9.728 & 1.0260 \\
& $(2.87,27.79)$ & $(2.71,22.36)$ & $(0.20,3.85)$ \\
\hline
\end{tabular}

estimate that unanticipated uncertainty explains about $20 \%$ of the variance of US GDP. $^{2}$

In summary, these results indicate that innovations to the volatility of the US real activity shock have important implications for the UK economy. In particular, this

2. In the Online Appendix we present a simple counterfactual experiment that shows that the US volatility shock was moderately important for GDP fluctuations in the United States and United Kingdom during the recent financial crisis. 
shock results in a fall in UK GDP and an increase in UK CPI. The impact on the US economy is estimated to be similar.

In an extensive sensitivity analysis (see Online Appendix) we show that this result is robust to various changes in the specification of the benchmark model. In particular, the same results are obtained if a larger VAR system that includes monetary and financial variables is used. Similarly, the impulse responses to the US GDP volatility shock are unaffected by the ordering of US GDP within the US block. Finally, the results survive the use of different detrending methods and alternative choice of prior distributions.

4.1.1. Time Variation in the VAR Coefficients. One possible shortcoming of the model in equation (5) is the fact that the VAR coefficients are fixed over time. In this section we relax this assumption and extend the model to allow for time-varying coefficients. In particular we estimate the following specification:

$$
Z_{t}=c_{S_{t}}+\sum_{j=1}^{P} \beta_{S_{t} j} Z_{t-j}+\sum_{j=0}^{J} \gamma_{j} \tilde{h}_{t-j}+\Omega_{t}^{1 / 2} e_{t} .
$$

Here $S_{t}$ follows a first-order $M$-state Markov chain with a restricted transition probability matrix with elements $p_{i j}=p\left(S_{t}=j \mid S_{t-1}=i\right)$ that are given by

$$
\begin{aligned}
p_{i j}>0 \text { if } \quad i=j \\
p_{i j}>0 \text { if } j=i+1 \\
p_{M M}=1 \\
p_{i j}=0 \text { otherwise. }
\end{aligned}
$$

In other words, this specification allows for $M-1$ unknown break points in the coefficients on the lagged endogenous variables (see Chib 1998). Given our relatively small sample (and thus the possibility of a small number of observations in each regime) we limit the maximum number of breaks to 2 in our application. ${ }^{3}$ The estimated DIC $\left(p_{D}\right)$ for the model with two regimes is -629.62 (239.10) while the estimates for the model with three regimes are 305.59 (381.10). Note that the model with two regimes is strongly preferred over the three-regime alternative. Note also that the DIC of the two regime model is higher than that of the fixed coefficient benchmark. This difference is driven by a deterioration in fit and an increase in model complexity once regime switching is allowed for. This result echoes the conclusions reached in Sims and Zha (2006) who show (using US data) that once heteroskedastic disturbances are allowed for, evidence for time variation is limited. Nevertheless it is interesting to examine

3. We use linearly detrended data in the switching model. We show in the Online Appendix that the same results are obtained using GDP growth and CPI inflation instead. The appendix also describes the extended Gibbs algorithm for this model. 

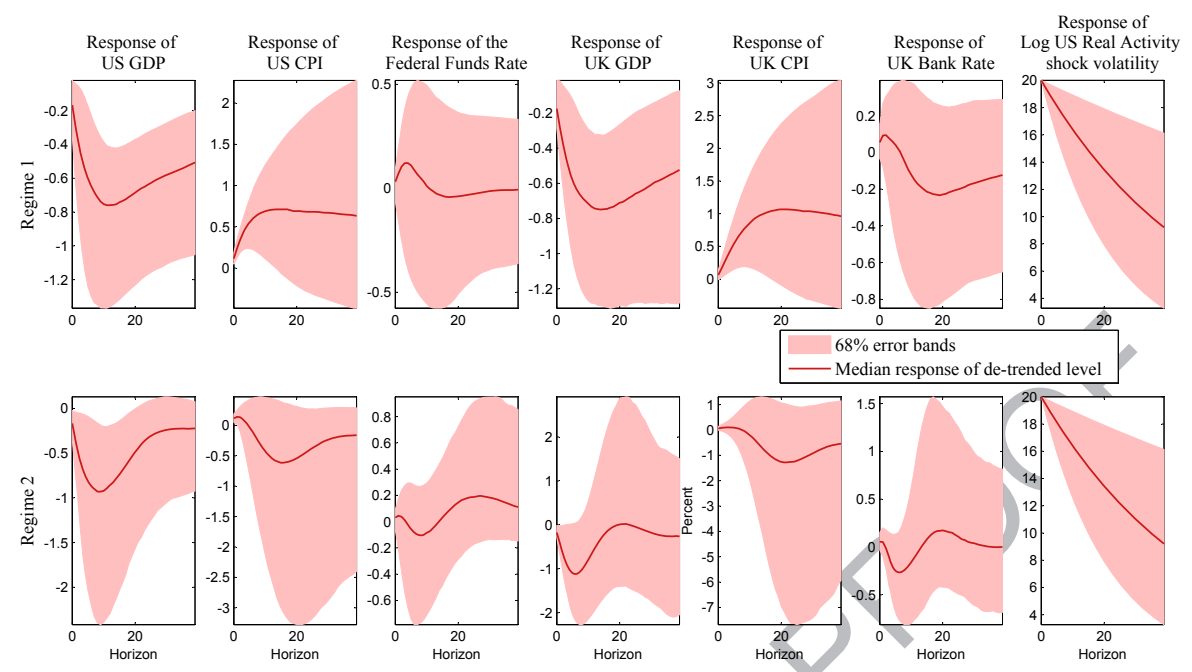

FIGURE 3. Results from the regime switching version of the benchmark VAR model. The impulse responses are expressed in percentage terms.

the results from the two-regime model presented in Figure 3. Note that the estimated date of regime change is 2001Q1. This break is associated with a striking change in detrended CPI in both countries with these variables moving below trend after this date (see Online Appendix). The regime-1 impulse responses shown in the top panel of the figure closely mimic the benchmark results. GDP falls in both countries in response to the volatility shock and CPI rises. The magnitude of the decline in GDP is larger in both countries in regime 2 . This possibly reflects the fact that the recent financial crisis (associated with a large increase in volatility and a large fall in GDP) is contained in this regime. The dynamics of CPI display more differences vis-à-vis regime 1 . There is an initial increase in CPI in both countries, but this then reversed in one to two years. However, in the case of both countries, the HPDIs associated with the regime-2 CPI response contains 0 over most of the horizon.

Keeping in mind the fact that the fixed-coefficient model is preferred to the regimeswitching model based on the DIC criteria, this change in the response of CPI represents a mild caveat to the main estimates previously presented.

\section{Explaining the Results: A Nonlinear DSGE Model}

\subsection{The Model}

We use a small open-economy DSGE model with stochastic volatility to study the theoretical plausibility of the results obtained from the SVAR model. In particular, 
TABLE 3. The description and value of the DSGE parameters that have been estimated using simulated methods of moments.

\begin{tabular}{|c|c|c|}
\hline Parameters & Description & Value \\
\hline$\xi_{d}$ & Calvo probability: domestic producer prices & 0.75 \\
\hline$\kappa_{d}$ & Indexation: domestic producer prices & 0.21 \\
\hline$\sigma_{g *}$ & STD: government spending shock & 0.0020 \\
\hline$\rho_{\sigma_{\lambda^{*}}}$ & Persistence: domestic prices markup SV shock & 0.98 \\
\hline$\rho_{\sigma_{w^{*}}}$ & Persistence: wages markup SV shock & 0.99 \\
\hline$\rho_{\sigma_{\psi *}^{*}}$ & Persistence: labor supply SV shock & 0.99 \\
\hline$\rho_{\sigma_{z^{*}}}$ & Persistence: productivity SV shock & 0.99 \\
\hline$\rho_{\sigma_{d^{*}}}$ & Persistence: preference SV shock & 0.97 \\
\hline$\rho_{\sigma_{g *}}$ & Persistence: government spending & 0.96 \\
\hline$\sigma_{\sigma_{\lambda^{*}}}^{s}$ & STD: domestic prices markup SV sho & 0.060 \\
\hline$\sigma_{\sigma_{w^{*}}}$ & STD: wages markup SV shock & 0.062 \\
\hline$\sigma_{\sigma_{* *}}$ & STD: labor supply SV shock & 0.070 \\
\hline$\sigma_{\sigma_{z^{*}}}$ & STD: productivity SV shock & 0.065 \\
\hline$\sigma_{\sigma_{d^{*}}}$ & STD: preference SV shock & 0.085 \\
\hline$\sigma_{\sigma_{g *}}$ & STD: government spending SV shock & 0.065 \\
\hline
\end{tabular}

we examine which volatility shocks in the DSGE model can generate a negative comovement between output and inflation as suggested by the VAR results previously described.

The structural model used in this study is a simplified version of the model developed by Adolfson et al. (2007). Our specification does not contain capital dynamics and, instead of assuming exogenous driving processes for all foreign variables (Justiniano and Preston 2010b; Adolfson et al. 2007), we explicitly model the foreign economy (Bauerle and Menz 2008; Justiniano and Preston 2010a). ${ }^{4}$ The model is described in detail in the longer online version of the paper. Here we provide a summary of the key features and present the key equations in Tables 2 and 3 in the online appendix. Following Christiano, Eichenbaum, and Evans (2005) and Smets and Wouters (2007) both domestic and foreign economies are characterized by a number of nominal and real frictions such as sticky prices, sticky wages, working capital-firms borrow money from a financial intermediate to finance part of their wage bill—and habit persistence. Moreover, both economies are populated by a continuum of infinitely lived households that consume and supply labor. Domestic and foreign households have monopoly power over their labor and they set wages based on Calvo

4. We abstract from capital to make our model parsimonious and computationally tractable. In Section 7 of the Online Appendix we illustrate that the results are robust when capital is added to the model in a simple manner. 
type staggered pricing contracts and backward indexation rules. Domestic households can invest in either domestic or foreign one-period bonds, while foreign agents are restricted from holding domestic bonds. The interest rates on both domestic foreign bonds are subject to risk-premia, which are functions of the net foreign asset position and lagged deviations from the uncovered interest rate parity.

On the supply side of the economy, there is a continuum of monopolistically competitive firms producing a variety of domestic goods used for the production of the final good, which can be either consumed domestically by agents or the government or-in the domestic economy-be exported. There is also a monopolistically competitive retail sector, which consists of firms that buy a homogeneous good in the world market that it is turned into a differentiated consumption good. All sectors are assumed to follow Calvo staggered pricing schemes and backward indexation rules.

Monetary authorities in both countries adjust their instruments-short-term interest rates-based on a Taylor type policy rule. Additionally, we assume that domestic authorities respond to real exchange variations to reduce the stabilization tradeoff between inflation and output caused by incomplete pass-through (see Gali and Monacelli 2005). The foreign economy is subject to six heteroskedastic disturbances (government spending, consumption preference, labor supply, price markup, wage markup, and productivity), while the domestic economy is affected by seven heteroskedastic shocks (government spending, consumption preference, labor supply, domestic price markup, import price markup, export price markup, wage markup, and productivity).

\subsection{Calibration}

In order to ensure that the structural model displays features of the actual data we select the parameters of the foreign stochastic volatility processes (government spending, consumption preference, labor supply, price markup, wage markup, and productivity), the parameters of the foreign price Phillips curve and the standard deviation of the government spending (level) shock to match the standard deviation and the first-order auto-correlation of the linear detrended US GDP, US CPI, and the Federal Funds rate via a simulated methods of moments (SMM) exercise. Since our focus is on the impact of foreign shocks on the domestic economy, we "switch off" domestic shocks in the SMM optimization and use just the foreign economy block of the model to match the US data moments. This simplification reduces the computer memory requirements for this exercise and makes the SMM minimization feasible in a reasonable length of time. The moments presented in Table 4 show that the DSGE model does a fairly good job at matching the data moments. ${ }^{5}$

The remaining parameters are calibrated using values from existing studies. Details of the calibration are presented in Section 6 of the Online Appendix.

5. The exact simulation steps to produce Table 4 are discussed in Section 5 of the Online Appendix. All the calculations have been implemented using Dynare 4.4.0 and the codes are available online. 
TABLE 4. Second moments in the model and the data. STD refers to standard deviation, while AR(1) is the first-order partial autocorrelation.

\begin{tabular}{|c|c|c|c|c|}
\hline \multirow[b]{2}{*}{ Variables } & \multicolumn{2}{|c|}{ Model } & \multicolumn{2}{|c|}{ Data } \\
\hline & STD & $\operatorname{AR}(1)$ & STD & $\operatorname{AR}(1)$ \\
\hline US GDP & 3.157 & 0.993 & 3.365 & 0.966 \\
\hline US inflation & 0.822 & 0.936 & 0.774 & 0.742 \\
\hline US policy rate & 0.846 & 0.962 & 0.776 & 0.949 \\
\hline UK GDP & 0.703 & 0.976 & 3.757 & 0.967 \\
\hline UK inflation & 0.357 & 0.958 & 1.271 & 0.818 \\
\hline UK policy rate & 0.727 & 0.990 & 0.801 & 0.944 \\
\hline
\end{tabular}

The model is solved using third-order perturbation methods (see Judd 1998) since for any order below three, stochastic volatility shocks (our main objects of interest) do not enter into the decision rule as independent components. One difficulty of using these higher-order solution techniques is that paths simulated by the approximated policy function often explode. As explained by Kim et al. (2008), regular perturbation approximations are polynomials that have multiple steady states and can yield unbounded solutions. In other words, this approximation is valid only locally, and along the simulation path we may enter into a region where its validity is not preserved anymore.

To avoid this problem Kim et al. (2008) suggest to "prune" all those terms that have an order that is higher than the approximation order, while Andreasen, FernandezVillaverde, and Rubio-Ramirez (2013) show how this logic can be applied to any order. Although there are studies that question the legitimacy of this approach (see Haan and Wind 2010), it has by now been widely accepted as the only reliable way to get the solution of $n$ th-order approximated DSGE model (where $n>1$ ).

Finally, we follow Fernandez-Villaverde et al. (2011b) and generate the responses of model variables to stochastic volatility shocks using generalized impulse responses developed by Koop, Pesaran, and Potter (1996). The exact details of this simulation are described in Section 5 of the Online Appendix.

\subsection{Impulse Response Analysis}

5.4.1. Supply Uncertainty Shocks. The first exercise examines how agents in both economies respond to foreign (US) supply type uncertainty shocks. Stochastic volatility shocks increase the uncertainty of foreign level supply shocks by $20 \%$. Figure 4 illustrates agents' optimal responses to (i) productivity uncertainty shocks (red solid line), (ii) wage markup and productivity uncertainty shocks (black dashed-dotted line), 

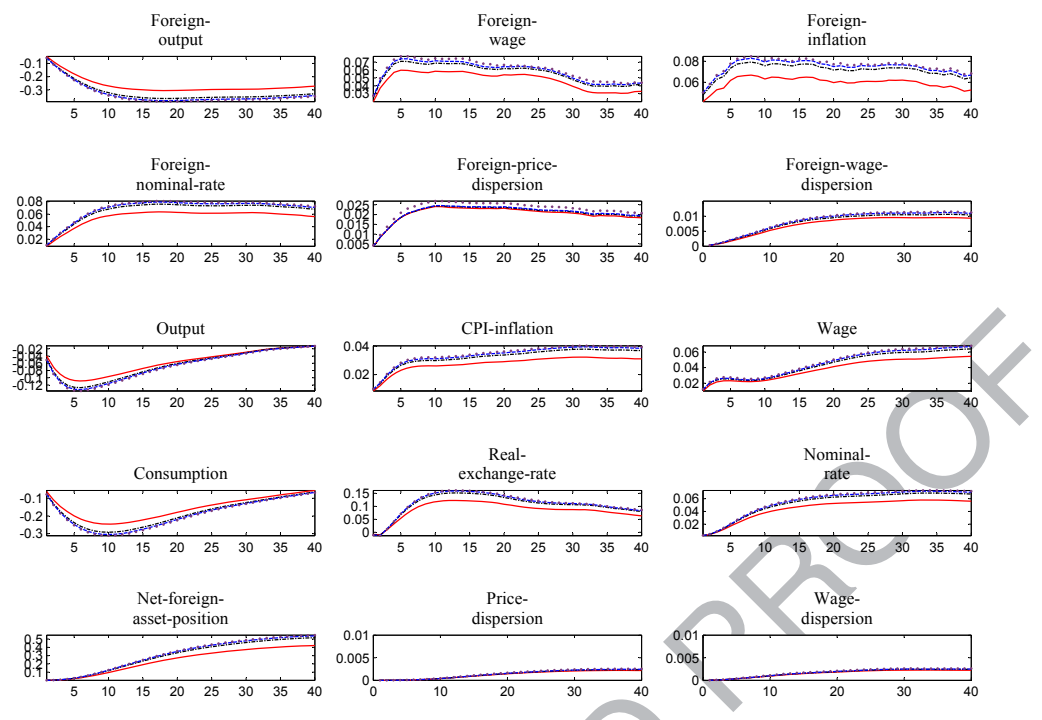

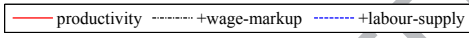

+price-markup

FIGURE 4. The response to supply type uncertainty shocks in the DSGE model. Uncertainty shocks increase supply shock volatility by $20 \%$. The impulse responses are expressed in percentage terms.

(iii) wage markup, productivity and labor supply uncertainty shocks (dark blue dashed line), and (iv) to wage markup, productivity, labor supply, and price markup uncertainty shocks (purple diamonds).

There is no doubt that these shock have a large effect on the economy, with the productivity uncertainty shock having the largest effect. Foreign output falls persistently below its steady state by almost $0.4 \%$ and it does not recover even ten years after the shock. The magnitude of the decline in GDP is smaller than the VAR estimate. This possibly reflects the fact that the DSGE model does not include features such as financial/banking frictions and thus does not contain mechanisms such as the financial accelerator. Foreign inflation rises by almost $0.1 \%$ above the target and stays elevated for more than 40 quarters. Another interesting observation is that the maximum impact of the shock takes place three years later.

The effects on the domestic economy are of similar order. Domestic GDP contracts by almost $0.1 \%$ while home inflation rises by $0.05 \%$. Recession and "stagflation" are also the key features of the VAR responses of UK GDP and inflation, making the supply stochastic volatility shocks a candidate structural interpretation of the empirical evidence. In contrast, as described in what follows, demand stochastic volatility shocks have a negligible impact on the two economies.

Foreign Economy. Consider the transmission mechanism underlying these results. Foreign agents are risk averse and respond to higher uncertainty by decreasing consumption and increasing savings, which leads to a reduction in foreign GDP. 
Although demand contracts, inflation increases because the (real) marginal cost rises due to higher (real) wage (see Figure 4). In our model we assume that wage and price decisions are staggered à la Calvo (Calvo 1983) and this creates wage and price dispersion. As explained in Ascari and Rossi (2012), Ascari and Sbordone (2013) and Schmitt-Grohe and Uribe (2007), in the Calvo model the cost of nominal rigidities (wage and price dispersion) creates a wedge between aggregate hours and aggregate output, making aggregate production less efficient (see market clearing condition in Table 3 in the Online Appendix). As we see in what follows, the higher the dispersion of prices and wages, the higher is the labor input needed to produce a given amount of aggregate output. Then it follows from the labor supply curve that, for any given level of output, price and wage dispersion increases the equilibrium real wage and hence the marginal cost of the firms.

To see this, consider the price that maximizes the expected profits of the firms that are allowed to reset prices:

$$
p_{t}^{\text {new,* }}=\lambda_{d t}^{*} \frac{E_{t} \sum_{j=0}^{\infty}\left(\beta \xi_{d}^{*}\right)^{j} \frac{\lambda_{t+j}^{*}}{\lambda_{t}^{*}} \pi_{t+j}^{\frac{\lambda_{d t}^{*}}{\lambda_{d t}^{*}-1}} m c_{t+j}^{*} y_{t+j}^{d *}}{E_{t} \sum_{j=0}^{\infty}\left(\beta \xi_{d}^{*}\right)^{j} \frac{\lambda_{t+j}^{*}}{\lambda_{t}^{*}} \pi_{t+j}^{\frac{1}{\lambda_{d t}^{*}-1}} y_{t+j}^{d *}} .
$$

Here for reasons of simplicity and without loss of generality we ignore indexation. Note that $\lambda_{d t}^{*}$ denotes the foreign price markup shock, $\beta$ is the preference discount factor, $\xi_{d}^{*}$ is the probability of resetting foreign prices, $\lambda_{t}^{*}$ stands for the foreign marginal utility of consumption, $m c_{t}^{*}$ is used to denote foreign marginal cost, $\pi_{t}^{*}$ is foreign inflation and, finally, $y_{t}^{d *}$ is foreign output.

The numerator in equation (9) is the present discounted value of future marginal costs, while the denominator can be interpreted as the present discounted value of marginal revenues for a unit change in the optimal reset price. Future expected inflation rates enter both the numerator and the denominator, affecting the relative weights on future variables. The intuition behind this is simple. Firms are aware that they may be stuck with the price set in the current period while inflation will reduce their markup as time progresses. They, therefore, discount future marginal costs taking into account future expected inflation rates. From equation (9) it is clear that the higher these future expected inflation rates, the higher the relative weights on expected future marginal costs, implying that firms become more forward-looking and place more weight on the future economic conditions than current ones. In other words, uncertainty becomes more important. From equation (9) we also see that firms place more weight on the marginal cost $\left(\lambda_{d t}^{*}\right) /\left(\lambda_{d t}^{*}-1\right)$ as compared to the marginal revenue $1 /\left(\lambda_{d t}^{*}-1\right){ }^{6}$ Thus an increase in uncertainty increases wage and price dispersion and that leads to higher marginal costs via the labor supply schedule. The higher weight attached to

6. As explained in Ascari and Sbordone (2013) and Schmitt-Grohe and Uribe (2007) this reflects the different elasticity of marginal costs and of marginal revenues to a change in the relative price on the expected profits. 
the marginal cost offsets the effects from the lower demand and causes $p_{t}^{\text {new,* }}$ and, consequently, inflation to rise. ${ }^{7}$

It remains, therefore, to show how an increase in uncertainty leads to higher $p_{t}^{\text {new,* }}$. We do that in two steps, first we identify the mapping between wage/price dispersion and marginal cost. Next we discuss how higher uncertainty is associated with higher wage/price dispersion. Let us consider the market clearing condition (see Table 3 in the Online Appendix)

$$
y_{t}^{d *}=\frac{z_{t}^{*} h_{t}^{d *}}{v_{t}^{p *}}=\frac{z_{t}^{*} h_{t}^{*}}{v_{t}^{p *} v_{t}^{w *}},
$$

where $v_{t}^{p *}$ and $v_{t}^{w *}$ are measures of the price and wage dispersion respectively. As shown by Schmitt-Grohe and Uribe (2007), $v_{t}^{p *}>1$ and $v_{t}^{w *}>1$. It is clear from the right-hand side of expression (10) that the higher the dispersion of prices and wages is, the higher is the labor input needed to produce a given amount of aggregate output. This translates into a higher equilibrium real wage (via the labor supply curve as agents dislike labor and demand higher compensation for the additional input) and, consequently, marginal cost and inflation. As shown in Figure 4, as the uncertainty of supply shocks increases wage and price dispersion rises leading to a higher wage, marginal cost and, finally, inflation. The policy rate rises in response to higher inflation and that causes the foreign GDP to contract further.

Domestic Economy. Domestic households and firms act in a manner that is similar to their foreign counterparts when they form decisions about consumption and prices, respectively. The persistent exchange rate depreciation leads to a series of trade surpluses that result in a higher stock of foreign debt. This echoes the discussion of Benigno, Benigno, and Nistico (2011) who argue that when the exchange rate is expected to depreciate, then investing in foreign bonds is a good strategy as it offers a better return when it is actually required. In other words, the depreciation of the exchange rate more than offsets the fall in the price of foreign assets and it generates a positive valuation effect. In this case an increase in the net foreign asset position "shields" the domestic economy from the consequences of the foreign uncertainty shock.

Although the foreign demand falls, exports increase due to the persistent exchange rate depreciation and that offsets some of the fall in the domestic GDP. The exchange rate depreciation induces import price inflation to rise and that puts further upward pressure on CPI inflation. Again the policy rate increases in response to higher inflation and that has an adverse effect on domestic GDP.

Demand Stochastic Volatility Shocks. In the Online Appendix we show what happens to both foreign and domestic economies when the uncertainty of US discount factor$\beta$-and government spending shocks rise by $20 \%$ (Figure 19). Interestingly, demand

7. As shown in Figure 3, there is weak empirical evidence that this transmission channel may be smaller in the later part of the sample, with US inflation falling in response to the volatility shock. Note, however, that this empirical model is rejected by the data. 
stochastic volatility shocks do not seem to have a significant impact on the economy when compared to supply uncertainty shock that we studied earlier. The impact of these shocks is about two or three orders of magnitude smaller than the supply uncertainty shocks.

This difference arises because of the following reason: a demand level shock moves output and inflation in the same direction and as a consequence the policy maker can easily offset the impact of this shock. For instance, a negative demand shock that lowers output also decreases inflation. Economic agents are less concerned about uncertainty regarding this shock as they are aware that monetary authorities will follow an expansionary policy to restore both output and inflation. Note that supply level shocks move output and inflation in different directions. Higher uncertainty regarding the realization of supply shocks implies that agents are less certain about the "support" they can receive from the monetary authority (in the face of negative shocks) and as a consequence the precautionary savings mechanisms are employed more intensively.

5.4.2. Discussion. The simulations reported previously represent fairly strong evidence in favor of the hypothesis that the real activity uncertainty shocks identified in our VAR model are consistent with uncertainty about supply type shocks in the DSGE model. As shown in the Online Appendix, the same results are obtained in a version of this model where (a) firms do not face working capital frictions or (b) we use a different risk premium function. In contrast, when we allow wages to adjust freely, then the impact of the foreign supply uncertainty shock is significantly smaller (see Figure 20 in the Online Appendix). This suggests that wage dispersion is more distortionary than price dispersion. In other words, frictions in the labor market are key drivers of the impact of the uncertainty shocks in our nonlinear DSGE model. Note that the analysis in Christiano, Eichenbaum, and Evans (2005), Smets and Wouters (2007) and Justiniano, Primiceri, and Tambalotti (2010) demonstrates convincingly that labor market frictions are needed in DSGE models in order to match the time series properties of wages in the US economy. Similarly, Harrison and Oomen (2010) present evidence on the importance of labor market frictions for the UK economy.

The model simulation results indicate that uncertainty can lead to large periods of stagflation, supporting the conclusions reached in Fernandez-Villaverde et al. (2011b) and Born and Pfeifer (2013). These papers provide further support for our argument that shocks that generate marginal cost uncertainty have the largest impact on the economy. Note, however, that from a quantitative point of view the impact of uncertainty in our model is larger than that reported by Born and Pfeifer (2013). This reflects the fact that Born and Pfeifer (2013) allow wages in their model to adjust freely-a strong assumption in the light of the results in Smets and Wouters (2007) and related papers.

Leduc and Liu (2012), instead, highlight the aggregate demand channel of uncertainty shock transmission and argue that when a DSGE model with price stickiness is augmented by search frictions, the demand effects of uncertainty are amplified. In contrast, the DSGE analysis in Basu and Bundick (2012) provides support for the idea that demand uncertainty shocks may have small effects. Basu and Bundick 
(2012) argue that uncertainty shocks have large effects when the monetary authority is constrained and cannot follow expansionary policy to unwind the impact of the shock. This is precisely the mechanism that leads to supply type uncertainty shocks having large effects in our modeling framework.

\section{Conclusion}

This paper investigates the international transmission of US real activity uncertainty shocks to the UK economy. To do this, we develop an open-economy structural VAR model that allows the volatility of US real activity shocks to be time varying and to have an impact on the endogenous variables. Innovations to US real activity shock uncertainty in the VAR model result in an increase in US and UK inflation and a fall in US and UK output.

We then use a nonlinear open-economy DSGE model to try and distinguish between different structural uncertainty shocks that are consistent with these empirical results. In particular, we consider an increase in foreign supply shock uncertainty and foreign demand shock uncertainty, respectively. We find that the sign and magnitude of the VAR responses are consistent with the supply uncertainty shocks. These shocks lead to higher inflation in both economies through higher marginal costs and to lower output due to precautionary savings.

\section{References}

Adolfson, Malin, Stefan Laseen, Jesper Linde, and Mattias Villani (2007). "Bayesian Estimation of an Open Economy DSGE Model with Incomplete Pass-Through.” Journal of International Economics, 72, 481-511.

Alexopoulos, Michelle and Jon Cohen (2009). "Uncertain Times, Uncertain Measures." Working Paper No. tecipa-352, University of Toronto, Department of Economics. Available at URL http://ideas.repec.org/p/tor/tecipa/tecipa-352.html.

Andreasen, Martin, Jesus Fernandez-Villaverde, and Juan Rubio-Ramirez (2013). "The Pruned State-Space System for Non-Linear DSGE Models: Theory and Empirical Applications.” NBER Working Paper No. 18983.

Aruoba, Boragan, Luigi Bocola, and Frank Schorfheide (2011). "A New Class of Nonlinear Times Series Models for the Evaluation of DSGE Models.” Working paper, University of Pennsylvania.

Asai, Manabu and Michael McAleer (2009). "Multivariate Stochastic Volatility, Leverage and News Impact Surfaces.” Econometrics Journal, 12, 292-309.

Ascari, Guido and Lorenza Rossi (2012). "Trend Inflation and Firms Price-Setting: Rotemberg Versus Calvo." Economic Journal, 122, 1115-1141.

Ascari, Guido and Argia M. Sbordone (2013). "The Macroeconomics of Trend Inflation.” Federal Reserve Bank Staff Report No. 628.

Baker, Scott R., Nicholas Bloom, and Steven J. Davis (2012). "Policy Uncertainty: A New Indicator." CentrePiece-The Magazine for Economic Performance 362, Centre for Economic Performance, LSE. Available at URL http://ideas.repec.org/p/cep/cepcnp/ 362.html.

Basu, Susanto and Brent Bundick (2012). "Uncertainty Shocks in a Model of Effective Demand." NBER Working Paper No. 18420. Available at URL http://ideas.repec.org/p/nbr/nberwo/ 18420.html. 
Bauerle, Gregor and Tobias Menz (2008). "Monetary Policy in a Small Open Economy Model: A DSGE-VAR Approach for Switzerland.” Working Paper No. 08.03, Swiss National Bank, Study Center Gerzensee.

Benigno, Gianluca, Pierpaolo Benigno, and Salvatore Nistico (2011). "Risk, Monetary Policy and the Exchange Rate." In NBER Macroeconomics Annual 2011, Volume 26. Available at URL http://ideas.repec.org/h/nbr/nberch/12420.html.

Berument, Hakan, Yeliz Yalcin, and Julide Yildirim (2009). "The Effect of Inflation Uncertainty on Inflation: Stochastic Volatility in Mean Model within a Dynamic Framework." Economic Modelling, 26, 201-207.

Bloom, Nicholas (2009). “The Impact of Uncertainty Shocks.” Econometrica, 77, 623-685.

Born, Benjamin and Johannes Pfeifer (2013). "Policy Risk and the Business Cycle." CESifo Working Paper No. 4336.

Calvo, Guillermo A. (1983). "Staggered Prices in a Utility-Maximizing Framework." Journal of Monetary Economics, 12, 383-398.

Canova, Fabio and Fernando J. Perez Forero (2012). "Estimating Overidentified, Nonrecursive, Time-Varying Coefficients Structural VARs." Economics Working Paper No. 1321, Department of Economics and Business, Universitat Pompeu Fabra. Available at URL http://ideas.repec.org/p/ upf/upfgen/1321.html.

Carlin, Bradley P., Nicholas G. Polson, and David S. Stoffer (1992). "A Monte Carlo Approach to Nonnormal and Nonlinear State-Space Modeling." Journal of the American Statistical Association, 87, 493-500.

Chib, Siddhartha (1998). "Estimation and Comparison of Multiple Change-Point Models." Journal of Econometrics, 86, 221-241.

Christiano, Lawrence, Martin Eichenbaum, and Charles Evans (2005). "Nominal Rigidities and the Dynamic Effects of a shock to Monetary Policy." Journal of Political Economy, 113, 1-45.

Christiano, Lawrence, Roberto Motto, and Massimo Rostagno (2014). "Risk Shocks." American Economic Review, 104(1), 27-65.

Cogley, T. and T. J. Sargent (2005). "Drifts and Volatilities: Monetary Policies and Outcomes in the Post-WWII U.S." Review of Economic Dynamics, 8, 262-302.

Colombo, Valentina (2013). "Economic Policy Uncertainty in the US: Does it Matter for the Euro Area?" Economics Letters, 121, 39-42.

Cushman, David O. and Tao Zha (1997). "Identifying Monetary Policy in a Small Open Economy under Flexible Exchange Rates.” Journal of Monetary Economics, 39, 433-448.

Fernandez-Villaverde, Jesus, Pablo Guerron-Quintana, Juan F. Rubio-Ramirez, and Martin Uribe (2011a). "Risk Matters: The Real Effects of Volatility Shocks." American Economic Review, 101(6), 2530-2561.

Fernandez-Villaverde, Jesus, Pablo A. Guerron-Quintana, Keith Kuester, and Juan Rubio-Ramirez (2011b). "Fiscal Volatility Shocks and Economic Activity." NBER Working Paper No. 17317. Available at URL http://ideas.repec.org/p/nbr/nberwo/17317.html.

Fernandez-Villaverde, Jesus, Pablo A. Guerron-Quintana, Juan Rubio-Ramirez, and Martin Uribe (2009). "Risk Matters: The Real Effects of Volatility Shocks.” NBER Working Paper No. 14875.

Fernandez-Villaverde, Jesus and Juan Rubio-Ramirez (2010). "Macroeconomics and Volatility: Data, Models, and Estimation." NBER Working Paper No. 16618. Available at URL http://ideas.repec.org/p/nbr/nberwo/16618.html.

Gali, Jordi and Tommaso Monacelli (2005). "Monetary Policy and Exchange Rate Volatility in a Small Open Economy.” Review of Economic Studies, 72, 707-734.

Haan, Wouter Den and Joris De Wind (2010). "How Well-Behaved are Higher-Order Perturbation Solutions?" DNB Working paper.

Harrison, Richard and Ozlem Oomen (2010). "Evaluating and Estimating a DSGE Model for the United Kingdom.” Bank of England working Paper No. 380.

Jacquier, E., N. Polson, and P. Rossi (1994). "Bayesian Analysis of Stochastic Volatility Models." Journal of Business and Economic Statistics, 12, 371-418.

Judd, Kenneth (1998). Numerical Methods in Economics. MIT Press. 
Justiniano, Alejandro and Bruce Preston (2010a). "Can Structural Small Open-Economy Models Account for the Influence of Foreign Disturbances?" Journal of International Economics, 81, 61-74.

Justiniano, Alejandro and Bruce Preston (2010b). "Monetary Policy and Uncertainty in an Empirical Small Open-Economy Model.” Journal of Applied Econometrics, 25, 93-128.

Justiniano, Alejandro, Giorgio Primiceri, and Andrea Tambalotti (2010). "Investment Shocks and Business Cycles." Journal of Monetary Economics, 57, 132-145.

Kim, Jinill, Sunghyun Kim, Ernst Schaumburg, and Christopher Sims (2008). "Calculating and using second-order accurate solutions of discrete time dynamic equilibrium models." Journal of Economic Dynamics and Control, 32, 3397-3414.

Kim, Soyoung (2001). "International Transmission of U.S. Monetary Policy Shocks: Evidence from VARs.” Journal of Monetary Economics, 48, 339-372.

Koop, Gary, M. Hashem Pesaran, and Simon M. Potter (1996). "Impulse Response Analysis in Nonlinear Multivariate Models.” Journal of Econometrics, 74, 119-147.

Koopman, Siem Jan and Eugenie Hol Uspensky (2000). "The Stochastic Volatility in Mean Model." Tinbergen Institute Discussion Paper No. 00-024/4.

Kwiatkowski, Lukasz (2010). "Markov Switching In-Mean Effect. Bayesian Analysis in Stochastic Volatility Framework." Central European Journal of Economic Modelling and Econometrics, 2, 59-94.

Leduc, Sylvain and Zheng Liu (2012). "Uncertainty Shocks are Aggregate Demand Shocks." Working Paper No. 2012-10, Federal Reserve Bank of San Francisco. Available at URL http://ideas.repec.org/p/fip/fedfwp/2012-10.html.

Lemoine, M. and C. Mougin (2010). "The Growth-Volatility Relationship: New Evidence Based on Stochastic Volatility in Mean Models.” Working Paper No. 285, Banque de France.

Mumtaz, Haroon and Laura Sunder-Plassmann (2010). "Time-Varying Dynamics of the Real Exchange Rate. A Structural VAR Analysis.” Bank of England Working Paper No. 382.

Primiceri, G. (2005). "Time Varying Structural Vector Autoregressions and Monetary Policy.” Review of Economic Studies, 72, 821-852.

Schmitt-Grohe, Stephanie and Martin Uribe (2007). "Optimal Simple and Implementable Monetary and Fiscal Rules.” Journal of Monetary Economics, 54, 1702-1725.

Scholl, Almuth and Harald Uhlig (2008). "New Evidence on the Puzzles: Results from Agnostic Identification on Monetary Policy and Exchange Rates." Journal of International Economics, 76, $1-13$.

Sims, Chris (1980). "Macroeconomics and Reality." Econometrica, 48, 1-48.

Sims, Christopher A. and Tao Zha (2006). "Were There Regime Switches in U.S. Monetary Policy?" American Economic Review, 96(1), 54-81.

Smets, Frank and Rafael Wouters (2007). "Shocks and Frictions in US Business Cycles: A Bayesian DSGE Approach.” American Economic Review, 97, 586-606.

Spiegelhalter, David J., Nicola G. Best, Bradley P. Carlin, and Angelika Van Der Linde (2002). "Bayesian Measures of Model Complexity and Fit." Journal of the Royal Statistical Society: Series B (Statistical Methodology), 64, 583-639.

\section{Supporting Information}

Additional Supporting Information may be found in the online version of this article at the publisher's website:

Title of supporting information 


\section{Queries}

Q1: Author: Is 'SV' in table 3 clear?

Q2: Author: Please provide title of supporting information. 


\section{Please correct and return this set}

Please use the proof correction marks shown below for all alterations and corrections. If you wish to return your proof by fax you should ensure that all amendments are written clearly in dark ink and are made well within the page margins.

\begin{tabular}{|c|c|c|}
\hline Instruction to printer & Textual mark & Marginal mark \\
\hline Leave unchanged & $\cdots$ under matter to remain & (1) \\
\hline $\begin{array}{l}\text { Insert in text the matter } \\
\text { indicated in the margin }\end{array}$ & $k$ & $\begin{array}{l}\text { New matter followed by } \\
h \text { or } h \otimes\end{array}$ \\
\hline Delete & $\begin{array}{l}\text { I through single character, rule or underline } \\
\text { or } \\
\square \text { through all characters to be deleted }\end{array}$ & $\sigma$ or $\sigma / \otimes$ \\
\hline $\begin{array}{l}\text { Substitute character or } \\
\text { substitute part of one or } \\
\text { more word(s) }\end{array}$ & $\begin{array}{l}\text { I through letter or } \\
\longmapsto \\
\text { through characters }\end{array}$ & $\begin{array}{l}\text { new character / or } \\
\text { new characters } /\end{array}$ \\
\hline Change to italics & — under matter to be changed & $\leftarrow$ \\
\hline Change to capitals & $\equiv$ under matter to be changed & $\equiv$ \\
\hline Change to small capitals & $=$ under matter to be changed & $=$ \\
\hline Change to bold type & $\sim$ under matter to be changed & $\sim$ \\
\hline Change to bold italic & $\bar{\sim}$ under matter to be changed & $\tilde{\omega}$ \\
\hline Change to lower case & Encircle matter to be changed & $\neq$ \\
\hline Change italic to upright type & (As above) & 4 \\
\hline Change bold to non-bold type & (As above) & nqu \\
\hline Insert 'superior' character & $\begin{array}{l}\text { I through character or } \\
L \text { where required }\end{array}$ & $\begin{array}{l}y \text { or } y \\
\text { under character } \\
\text { e.g. } y^{\prime} \text { or } y^{\prime}\end{array}$ \\
\hline Insert 'inferior' character & (As above) & $\begin{array}{l}\text { hor character } \\
\text { over } \\
\text { e.g. } \hat{\imath}\end{array}$ \\
\hline Insert full stop & (As above) & $\odot$ \\
\hline Insert comma & (As above) & , + n \\
\hline Insert single quotation marks & (As above) & $\begin{array}{l}\dot{y} \text { or } \dot{y} \text { and/or } \\
\dot{y} \text { or } \dot{x}\end{array}$ \\
\hline Insert double quotation marks & (As above) & $\begin{array}{l}\ddot{y} \text { or } \ddot{x} \text { and/or } \\
\ddot{y} \text { or } \ddot{x}\end{array}$ \\
\hline Insert hyphen & (As above) & 1 \\
\hline Start new paragraph & 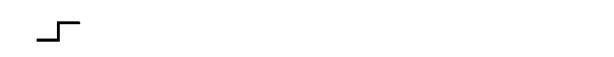 & 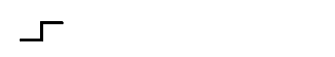 \\
\hline No new paragraph & 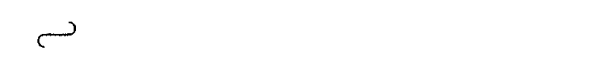 & 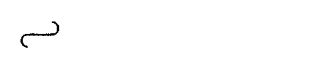 \\
\hline Transpose & ப & $\sqcup$ \\
\hline Close up & linking $\bigcirc$ characters & \\
\hline $\begin{array}{l}\text { Insert or substitute space } \\
\text { between characters or words }\end{array}$ & $\begin{array}{l}\text { I through character or } \\
\text { L where required }\end{array}$ & Y \\
\hline $\begin{array}{l}\text { Reduce space between } \\
\text { characters or words }\end{array}$ & $\begin{array}{l}\text { between characters or } \\
\text { words affected }\end{array}$ & $\uparrow$ \\
\hline
\end{tabular}

